\title{
Progress in ileal endogenous amino acid flow research in poultry
}

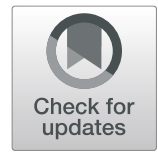

\author{
V. Ravindran
}

\begin{abstract}
The progress in our understanding of the endogenous protein concept over the past century is reviewed. Nondietary proteins found in the digesta at the terminal ileum of poultry, known as endogenous protein loss, are comprised of digestive secretions, mucus and sloughed gut epithelial cells. The measurement of this loss is of fundamental importance because it is an indicator of gut metabolism and is essential to adjust apparent estimates of ileal amino acid digestibility. The ileal endogenous amino acid losses comprise of two components, namely basal and specific losses. The basal losses are fixed and associated with feed dry matter intake, whereas the specific losses are variable and induced by the presence of dietary components such as fibre and anti-nutrients. Currently there is no methodology available to directly measure the specific endogenous losses and these losses are calculated by determining the basal and total (basal plus specific) losses and, then subtracting the basal losses from total losses. The seminal features, specific applications and shortcomings of available methodologies are briefly outlined as well as the practical challenges faced in using the published endogenous amino acid loss values for true digestibility corrections. The relevance of taurine as a component of endogenous protein flow in poultry is identified for the first time.
\end{abstract}

Keywords: Basal loss, Digestible amino acids, Endogenous amino acid losses, Poultry, Specific loss

\section{Introduction}

Endogenous protein loss, which links the gut physiology and protein nutrition, has proved to be an alluring subject of research for many years. Historically, the presence of undigested substances of digestive tract origin in the excretory products of animals and its relevance to the biological value of protein has long been known [1-3]. In poultry, the earliest work on the use of nitrogen-free diets was by Ackerson et al. [4] to study the variation in nitrogen excretion patterns with time and moulting. Bragg et al. [5] are credited with the first report of the quantification of endogenous amino acid losses in poultry and using them as correction factors in digestibility calculations. In their study, a nitrogen-free diet

Correspondence: V.Ravindran@massey.ac.nz

Monogastric Research Centre, School of Agriculture and Environment,

Massey University, Palmerston North 4442, New Zealand was fed to measure the metabolic and endogenous losses in colostomised birds over the total digestive tract.

Over the past two decades, the measurement of amino acid digestibility of ingredients for poultry has shifted to ileal level from the excreta, because of the variable and modifying effects of the hindgut microbiome on protein utilisation and the contribution of metabolic nitrogen due to urine contamination [6]. Currently the use of ileal digestibility values in feed formulation is the norm in the poultry industry and therefore the current review will focus on ileal endogenous losses instead of early research on metabolic and endogenous flow measurements at the excreta level.

During the digestion of ingesta, there is a continuous input of endogenous proteins, in the form of secretion of digestive enzymes and bile, shedding of mucus and desquamated enterocytes, into the lumen of the intestine. This input of endogenous proteins is copious and

(c) The Author(s). 2021 Open Access This article is licensed under a Creative Commons Attribution 4.0 International License, which permits use, sharing, adaptation, distribution and reproduction in any medium or format, as long as you give appropriate credit to the original author(s) and the source, provide a link to the Creative Commons licence, and indicate if changes were made. The images or other third party material in this article are included in the article's Creative Commons licence, unless indicated otherwise in a credit line to the material. If material is not included in the article's Creative Commons licence and your intended use is not permitted by statutory regulation or exceeds the permitted use, you will need to obtain permission directly from the copyright holder. To view a copy of this licence, visit http://creativecommons.org/licenses/by/4.0/ The Creative Commons Public Domain Dedication waiver (http://creativecommons.org/publicdomain/zero/1.0/) applies to the data made available in this article, unless otherwise stated in a credit line to the data. 
estimated to be as much as four- or five-fold of the amount of ingested proteins [7]. These endogenous sources mix with dietary protein and are digested, and the resulting amino acids are absorbed. The magnitude of reabsorption of endogenous proteins up to the ileal level in poultry is not known. In pigs, Souffrant et al. [8] estimated that $79 \%$ of the gross endogenous secretion in pigs is reabsorbed, but the degree of re-absorption varies depending on the relative ratio of individual endogenous components and their point of entry into the gut, being high with digestive enzymes and lower with mucin. Endogenous protein flow measured at the terminal ileum, therefore, represent the net balance between ingested protein and endogenous protein secretions minus absorption of dietary protein and reabsorption of endogenous protein [9]. The unabsorbed endogenous portion that passes beyond the ileum is fundamentally lost to the animal and referred to as inevitable, obligatory losses.

Accurate quantification of endogenous amino acid (EAA) losses is important for several reasons. First, the correction for these unavoidable losses is required for the calculation of true amino acid digestibility of feed ingredients. Second, it is necessary for the determination of protein and amino acid requirements by the factorial method. Third, these losses have significant ramifications in terms of the metabolic cost associated with protein synthesis and turnover in the gut. Finally, the measurement of these losses and better understanding of the factors by which they are influenced provide an effective strategy to improve the efficiency of protein and amino acid utilisation.

It is recognised that EAA losses are influenced primarily by feed intake and secondarily by the inherent composition of the feed ingredient or diet. These two fractions are conveniently categorised to as basal (also known as non-specific) and specific EAA losses, respectively [10]. Basal endogenous losses are defined as those inevitable losses closely associated with the metabolic functions of the animal and are independent of the diet type. These losses represent the minimum losses that can be expected under any feeding situation. Specific losses, in contrast, are diet-related resulting from the presence of specific dietary components such as sources and amounts of fibre and various anti-nutritional factors (e.g. phytate, trypsin inhibitor, lectins etc.). Currently there is no methodology available to directly quantify the specific EAA losses. These losses, however, can be calculated by determining the total (basal plus specific) losses and then subtracting the basal losses from total losses.

The microcosm of endogenous protein flow is too extensive to comprehensively review herein and it is necessary, therefore, to treat the subject selectively. The review of Sibbald [11] provides an excellent coverage of early research on metabolic and endogenous losses at the excreta level in poultry. Subsequent reviews have focused on ileal endogenous losses and several exhaustive contributions are available [12-16], which provide background information for the present paper. In the current review, it seems appropriate to focus on the progress made on the measurement of ileal EAA in poultry and on the understanding of factors influencing EAA losses, followed by challenges faced by the industry in translating the endogenous flow data into practical application.

\section{Sources of endogenous secretions}

The first step in a discussion on EAA flow should be what constitutes endogenous proteins. These proteins originate predominantly from various digestive secretions (bile, pancreatic enzymes and, gastric and intestinal secretions), mucoproteins and desquamated intestinal epithelial cells. Microbial mass also contributes significantly to the nitrogen found in the ileal digesta $[17,18]$, but paradoxically not considered neither as endogenous nor as dietary origin.

As mentioned, EAA flow determined at the terminal ileum is the net result of the digestive dynamics of endogenous sources along the digestive tract and represents the algebraic difference between that secreted and absorbed. The source of endogenous proteins and the entry point into the digestive tract appears to be critical in determining this dynamic. When digestive enzymes dominate the endogenous flow, the proteins pass through the duodenum and jejunum where there is greater opportunity for digestion and absorption. In contrast, if mucus secretion or desquamation is significant, particularly if they occur distal to the duodenum, then the opportunity for digestion is lower and relatively higher endogenous losses will be inevitable at the ileal level. Owing to this complicated nature of digestion trends, it is difficult to assess the true contribution of each endogenous protein source.

Interestingly, studies with poultry have shown that the amino acid composition of ileal endogenous protein is generally constant, independent of diet and method of determination. As shown in Table 1, the class of chicken (broilers, layers or roosters) has little influence on the EAA profile and, the profiles of chickens and pigs are remarkably similar.

The most abundant amino acids in the ileal endogenous protein of both species were glutamic acid, aspartic acid, threonine, proline, serine and glycine. These amino acids are found in high concentrations in intestinal and pancreatic secretions, and mucoproteins (Table 2), confirming that these are the major components of endogenous protein.

Threonine, proline, serine and glutamic acid predominate intestinal mucus glycoproteins [24], indicating 
Table 1 Amino acid composition of basal ileal endogenous protein ( $\mathrm{g} / 100 \mathrm{~g}$ crude protein) in different classes of poultry, in comparison to those reported in pigs (all measured using the enzyme hydrolysed casein method)

\begin{tabular}{lllll}
\hline Amino acid $^{\mathbf{a}}$ & Broilers $^{\mathbf{b}}$ & Layers $^{\mathbf{b}}$ & Roosters $^{\mathbf{b}}$ & Growing pigs $^{\mathbf{c}}$ \\
\hline Aspartic acid & 7.2 & 7.4 & 7.9 & 7.7 \\
Threonine & 6.3 & 7.5 & 7.0 & 5.1 \\
Serine & 6.0 & 6.2 & 8.3 & 6.7 \\
Glutamic acid & 13.7 & 10.5 & 15.1 & 16.5 \\
Proline & 7.8 & 6.4 & 6.6 & 11.8 \\
Glycine & 5.2 & 5.8 & 6.2 & 7.8 \\
Alanine & 3.4 & 5.2 & 3.1 & 3.7 \\
Valine & 4.6 & 4.9 & 5.5 & 4.0 \\
Isoleucine & 3.4 & 3.3 & 4.7 & 3.4 \\
Leucine & 4.7 & 4.9 & 4.7 & 4.1 \\
Tyrosine & 2.6 & 2.7 & 2.3 & 2.2 \\
Phenylalanine & 3.4 & 3.4 & 2.9 & 2.4 \\
Histidine & 2.3 & 2.4 & 2.2 & 2.0 \\
Lysine & 3.0 & 3.2 & 3.6 & 3.0 \\
Arginine & 3.0 & 3.0 & 2.5 & 2.7 \\
Methionine & 1.3 & 1.2 & 1.1 & - \\
Cysteine & 2.0 & 2.3 & 2.1 & - \\
\hline The & 2.3 & &
\end{tabular}

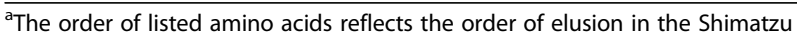
LC-MS and Dionex HPLC system used in our labs. It must be noted that the order of elution will change depending on depending on methods and conditions

${ }^{\mathrm{b}}$ Ravindran and Hendriks [19]

'Jansman et al. [20]

greater presence of mucins, which are thought to be resistant to enzymatic hydrolysis, in the ileal protein flow [25]. Glycine, the abundant amino acid in biliary secretions of pigs, escapes reabsorption as deconjugated glycine [26] and contributes to the high glycine content of endogenous protein. However, this is not the case in poultry where the bile acid conjugation is almost exclusively with taurine [27]. In all poultry studies, the high concentration of glycine in EAA is attributed to bile secretions $[13,14,19]$. None of the EAA data in poultry to date have considered or reported taurine values. Clearly in future EAA studies with poultry, taurine estimates must be included, and this will give important information on the contribution of bile secretions to ileal endogenous losses.

Depending on the amount and type of fibre and specific anti-nutrient, the effect on components of endogenous secretion differ. For example, the effect of trypsin inhibitor appears to be largely on increasing pancreatic secretions [28], whereas that of insoluble fibre may be mainly on mucin and of soluble, viscous fibre may possibly have a major effect of bacterial component [12].
Measurement of basal endogenous protein losses

The measurement and relevance of basal EAA losses in protein nutrition are dealt elsewhere $[14,15]$. The basal EAA estimates are needed to calculate the specific losses from total losses.

A summary of various available methodologies for the quantification of basal losses is presented in Table 3. Of these, feeding of a protein-free diet is the most widely used method because of its simplicity. The basic assumption is that a meal devoid of protein still provides adequate stimulus in the gastrointestinal tract to secrete endogenous proteins. It must be recognised, however, that the absence of protein will profoundly change nitrogen balance and whole-body protein synthesis, and the animal no longer could be considered as physiologically normal.

In recent decades, with the increasing acceptance of ileal-based digestibility concept, the site of measurement of endogenous flow has been moved from the excreta to ileal level [31]. In broiler chickens, basal ileal EAA losses have been reported to range from $3.08 \mathrm{~g} / \mathrm{kg}$ dry matter intake (DMI) for the protein-free diet to $8.81 \mathrm{~g} / \mathrm{kg}$ DMI for the highly digestible protein method [32]. The reliability of available methods, under a given set of dietary conditions, had been an impediment in the measurement of basal EAA losses and, as with most biological responses, the perfect technique for measuring EAA losses is yet to be developed.

\section{Measurement of total endogenous protein losses}

Two methodologies, namely isotopic and guanidination techniques, are available for the measurement of total endogenous losses.

\section{Techniques involving isotope markers}

Substantial research investment was made during the 1980's and 1990's to measure the total EAA in pigs using either stable $\left({ }^{15} \mathrm{~N}\right)$ or radioactive $\left({ }^{14} \mathrm{C},{ }^{35} \mathrm{~S},{ }^{75} \mathrm{Se}\right)$ isotopes. The ${ }^{15} \mathrm{~N}$ isotope dilution technique of Souffrant et al. [33] was particularly popular and employed by a number of researchers $[34,35]$ to differentiate endogenous proteins from non-digested dietary proteins in the ileal digesta of pigs. The method involves the perfusion of ${ }^{15} \mathrm{~N}$-labelled leucine into the blood of pigs consuming the test protein. The labelled amino acid is incorporated in the endogenous secretions and the dilution of ${ }^{15} \mathrm{~N}$ measured in the digesta gives an estimation of the amount of endogenous nitrogen. The data from isotope dilution demonstrated that the recovery of endogenous proteins in the ileal digesta was higher than those determined by feeding a protein-free diet. Most of these isotopic studies have been conducted with pigs and only two with poultry $[36,37]$. 
Table 2 Amino acid profile ( $\mathrm{g} / 100 \mathrm{~g}$ amino acids) of different endogenous secretions

\begin{tabular}{|c|c|c|c|c|}
\hline Amino acid & Pancreatic secretions $^{a}$ & Bile (pigs) $^{b}$ & Bile (broilers) ${ }^{c}$ & Mucin $^{d}$ \\
\hline Aspartic acid & 12.5 & 0.4 & 2.1 & 7.8 \\
\hline Threonine & 5.2 & 0.3 & 1.5 & 16.4 \\
\hline Serine & 6.9 & 0.3 & 1.6 & 10.9 \\
\hline Glutamic acid & 10.3 & 1.1 & 3.2 & 10.1 \\
\hline Proline & 5.0 & 0.3 & 1.4 & 12.0 \\
\hline Glycine & 6.2 & 95.0 & 1.9 & 5.5 \\
\hline Alanine & 5.4 & 0.0 & 1.1 & 7.4 \\
\hline Valine & 7.2 & 0.3 & 1.7 & 5.9 \\
\hline Isoleucine & 5.9 & 0.2 & 1.0 & 3.0 \\
\hline Leucine & 8.3 & 0.4 & 1.8 & 5.7 \\
\hline Tyrosine & 5.7 & 0.2 & 1.1 & 3.2 \\
\hline Phenylalanine & 4.4 & 0.2 & 1.0 & 3.5 \\
\hline Histidine & 2.6 & 0.2 & 0.8 & 1.7 \\
\hline Lysine & 5.1 & 0.3 & 1.2 & 2.8 \\
\hline Arginine & 5.1 & 0.3 & 2.5 & 3.5 \\
\hline Taurine & - & - & 73.7 & - \\
\hline Methionine & 1.1 & 0.1 & 0.7 & 0.8 \\
\hline Cysteine & 1.7 & 0.6 & 1.7 & 10.0 \\
\hline
\end{tabular}

${ }^{\mathrm{a}}$ Pancreatic secretions, pigs; Corring and Jung [21]

buste [22]

'Massey University, unpublished data

${ }^{\mathrm{d}}$ Mucin from the small intestine, pigs; Lien et al. [23]

Though attractive, this technique suffers from several constraints, because the determination of ${ }^{15} \mathrm{~N}$ enrichment of endogenous secretions is demanding and burdensome. The inability to measure the recovery of all individual amino acids in ileal digesta $[34,38]$ and the rapid precursor pool recycling [33] are other drawbacks. These limitations have been elegantly discussed by Leterme et al. [39] and Moughan et al. [40]. In particular, standardisation of conditions such as feeding frequency, diet type, infusion protocol, rate of tracer infusion, sampling procedures, sample preparation and choice of precursor pool(s) is imperative if reliable comparisons of data from different laboratories are to be made [41].

$\mathrm{Xu}$ et al. [42] described an alternative isotopic method involving a single muscular injection of ${ }^{3} \mathrm{H}$-labelled

Table 3 Methods used for the determination of basal and total endogenous amino acid losses in poultry

\begin{tabular}{ll}
\hline Item & Methods \\
\hline Basal losses & $\cdot$ Fasting of birds for $48 \mathrm{~h}^{\mathrm{a}}$ \\
& $\cdot$ Feeding of a protein-free diet \\
& $\cdot$ Feeding of diets with very low levels of protein \\
& $\cdot$ Protein-free diet supplemented with synthetic amino acids \\
& $\cdot$ Protein-free diets with intravenous amino acid infusion \\
& $\cdot$ Natural proteins devoid of specific amino acids \\
& $\cdot$ Enzyme hydrolysed casein ${ }^{\mathrm{b}}$ and ultrafiltration \\
& $\cdot$ Feeding of highly digestible protein, e.g. wheat gluten, soy protein isolate, casein ${ }^{\mathrm{b}}$ \\
& $\cdot$ Linear regression, following feeding of diets containing graded levels of specific ingredient \\
& $\cdot$ Homoarginine \\
Total losses & $\cdot$ Isotope-labelled markers
\end{tabular}

${ }^{a}$ Specific to precision-fed rooster assays $[29,30]$ and measured in the excreta. Measurement units are function of time (mg/bird/d) rather than intake (mg/kg dry matter intake) and cannot be used as correction factor in other digestibility assays

${ }^{\mathrm{b}}$ These proteins are assumed to be (almost) $100 \%$ digestible and that excreted amino acids therefore represent endogenous losses 
leucine to measure EAA losses in broilers. It was stated that this novel approach overcomes most of the limitations of isotope dilution techniques and, according to Makkar [43], is thought to be as effective.

\section{Homoarginine technique}

An innovative approach, using homoarginine (HA) as a marker, to determine EAA losses was proposed by Hagemeister and Erbersdobler [44]. In this method, $\varepsilon$-amino group of lysine in dietary proteins are converted into HA by the guanidination reaction, involving treatment with O-methylisourea under alkaline conditions. After the labelled protein is fed, endogenous losses of amino acids are determined by comparing amino acid: HA ratios in the diet and ileal digesta. Homoarginine is not found in normal feedstuffs. It is digested and absorbed in a manner like other amino acids [31], but does not reappear in endogenous secretions into the gut and this unique feature enables the calculation of total EAA losses.

The HA method is based on following premises, most of which have been tested and found to be tenable, and have been explored at length [13, 40, 45-47].

1. Absorbed HA is not incorporated into tissue proteins and therefore not re-cycled into the intestine [48].

2. The guanidinated protein is homogeneously and randomly labelled with $\mathrm{HA}$, a premise proven to be true for purified proteins [31].

3. Homoarginine behaves within the digestive tract like other amino acids: Homoarginine incorporated into dietary proteins is released during digestion and then absorbed at rates like those of other amino acids [49].

4. Homoarginine per se does not influence endogenous protein losses; the fact that HA behaves in the small intestine like a typical amino acid suggests that HA per se has no effect on endogenous protein output.

5. Homoarginine is not preferentially metabolised by gut microflora [31].

6. Homoarginine is easily and accurately determined by the ion-exchange chromatography as a typical amino acid during routine amino acid analysis without the need for specific hydrolysis or separation procedures.

Guanidination has been investigated in a diverse group of feed proteins, with widely differing lysine concentrations. The degree of conversion of lysine to HA varies greatly depending on the protein source, ranging from $83 \%$ to $100 \%$ for purified proteins, $40 \%-88 \%$ for common protein meals to $57 \%-63 \%$ for cereals [31, 50-54].
The factors affecting the extent of conversion are $\mathrm{pH}$ of the reaction mixture, the duration and temperature of incubation and, the ratio of $\mathrm{O}$-methylisourea and lysine in the reaction mixture. The optimal guanidination conditions vary depending on the protein source and sometimes within the protein source.

It must be noted that, as per definition, only the endogenous loss of lysine is directly determined in the guanidination method [45]. The losses of other amino acids are then derived indirectly from based on the ratio of HA to amino acids in the guanidinated protein and ileal digesta. A special attribute of the HA method is that it can be used to determine the EAA secretions in animals given protein sources which contain fibre, antinutritional factors or both. This approach has been employed to measure total EAA losses in poultry [31, 55-57]. These studies confirm that ileal EAA losses determined by HA method are substantially higher than those determined by the protein-free diet. For example. Siriwan et al. [31] and Ravindran et al. [57] reported that values for EAA losses in broilers obtained using guanidinated casein were 2-3 times as much as those estimated either by feeding a nitrogen-free diet or by extrapolation to zero nitrogen intake.

Overall, in principle, the isotopic techniques and guanidination reaction are appealing for the measurement of total endogenous protein flows in animals that are in a physiologically normal state, following the feeding of wide range of protein sources. Both, however, suffer from practical limitations. Both are tedious, timeconsuming and costly. Isotope dilution techniques require highly specialised personnel, equipment and facilities. Estimates from both approaches provide direct information only of the endogenous flow of one amino acid-lysine in the case of HA method and leucine in most cases of isotopes; flows of other amino acids are then calculated assuming a constant composition of endogenous protein but this assumption may not be valid for specific losses since, as discussed earlier, different anti-nutrients and fibre sources have diverging effects on individual components of the endogenous protein.

\section{Regression method}

The regression method has been promoted in some studies for the direct measurement of true amino acid digestibility of feed ingredients [58-61]. It has also been suggested that the total (basal plus specific) ileal EAA losses can be determined under normal protein alimentation conditions using this method [58]. In this method, diets containing graded levels of AA from an ingredient are fed and a linear relationship between dietary nutrient input and their output in ileal digesta is established. This relationship permits the determination of diet independent theoretical total (basal plus specific) EAA losses and 
simultaneous measurement of true amino acid digestibility of the feed ingredient, as the intercept and slope of the regression, respectively.

Although, in theory, the true amino acid digestibility of the feed ingredient is directly determined, the laboriousness and cost involved limit its wider acceptance in nutritional research. Although the method overcomes the issue of physiological aberration, it incorrectly assumes that the EAA flow does not vary with the amount of protein fed [40]. Moreover, in several studies, regression method has yielded EAA estimates similar to that of protein-free diets [58] disputing its potential usefulness. A more important concern is the negative estimates reported for EAA loss in some studies. The notion that EAA losses can be negative is physiologically untenable and suggestive of the inherent limitation of the regression method [40]. Similar negative estimates for endogenous losses of phosphorus, with the regression method, have also been reported [62-64]. Overall, the negative estimates call the usefulness of this method to measure EAA losses into question.

\section{Data on specific ileal endogenous amino acid losses}

The measurement of specific feed-induced EAA losses is both of practical as well as scientific interest, because of its consequences on intestinal dynamics, protein nutrition and energy costs [65]. However, published data on specific losses in poultry are non-existent, due largely to the complexity and specialised requirements of the methods to measure total EAA losses. Unpublished results from the Author's group, summarised in Table 4, indicate that the specific EAA losses vary between feedstuffs, reflecting the effects of fibre and antinutrients on endogenous protein secretion.

\section{Influence of dietary components}

While studies on total EAA losses induced by specific components present in native ingredients are limited, research to quantify the effects of added purified dietary components has attracted some attention [12]. Large numbers of studies have examined the influence of pure forms of fibre, lipids and individual anti-nutrients on
EAA losses, by the addition of these compounds on top of diets designed to measure basal losses (e.g. proteinfree diet, casein diet) or total losses (e.g. guanidinated casein, isotopic dilution). Select examples are summarised in Table 5 and the results of these studies, in general, confirm the EAA loss responses associated with a range of dietary factors.

\section{Practical application of endogenous flow data}

The quantification of ileal EAA flow is critical for better understanding of the efficiency of nitrogen utilisation. The endogenous nitrogenous components leaving the terminal ileum are lost to the animal and, represent a net cost to the environment and, importantly, to productivity and profitability. Measurement and comprehension of the factors influencing these losses provide an important practical strategy to enhance the efficiency of nitrogen use in the farm. These losses not only have direct caloric consequence for the digestible energy lost via endogenous amino acids $[67,68]$, but also ramifications on the energy cost associated with protein synthesis and cell turnover in the gut.

The prime application of the quantified EAA losses is for the correction of apparent digestibility to true digestibility values. It has now accepted that the ileal digestibility determined with growing birds are preferable over those determined at the total tract level. Accordingly, the apparent ileal digestibility must be corrected for ileal EAA losses and that the use of apparent values in feed formulations must be disbanded [76]. For reasons presented above, basal losses, as opposed to specific losses, are more relevant for such corrections. But the challenge is to agree on which basal EAA loss estimate should be considered. The question is whether to use the estimate from protein-free DMI or that from protein-containing DMI because diets always contain protein and the methods used for the determination of basal losses should use diets that contain protein [76, 77]. In the pig industry, there is consensus that a constant basal estimate based on the feeding of protein-free diets as being the valid value to correct for basal endogenous EAA losses [78] and the digestibility term 'standardised' has been put forward to replace the original term 'true' [79].

Table 4 Specific feed-induced ileal endogenous protein losses ( $\mathrm{g} / \mathrm{kg}$ dry matter intake) in broiler chickens ${ }^{\mathrm{a}}$

\begin{tabular}{llll}
\hline Feedstuff & Total losses $^{\mathbf{b}}$ & Basal losses $^{\mathbf{c}}$ & Specific losses $^{\mathbf{d}}$ \\
\hline Soybean meal, $480 \mathrm{~g} / \mathrm{kg}$ crude protein & 14 & 12 & 2 \\
Soybean meal, $440 \mathrm{~g} / \mathrm{kg}$ crude protein & 21 & 12 & 9 \\
Canola meal & 28 & 12 & 16 \\
Cottonseed meal & 39 & 12 & 27 \\
\hline
\end{tabular}

aniversity of Sydney, Camden, NSW, Australia, unpublished data

${ }^{\mathrm{b}}$ Following feeding of guanidinated proteins

${ }^{c}$ Following feeding of enzyme-hydrolysed casein

${ }^{\mathrm{d}}$ Total losses minus basal losses 
Table 5 Studies evaluating the effects of pure forms of dietary components on ileal endogenous amino acid losses in broiler chickens - select examples

\begin{tabular}{lll}
\hline References & Background & Factors examined \\
\hline Danicke et al. [36] & ${ }^{15}$ N-isotope dilution & Lipids \\
Angkanaporn et al. [55] & Guanidinated casein & Non-starch polysaccharide \\
Siriwan et al. [66] & Guanidinated casein & Fibre level \\
Cowieson and Ravindran [67] & Enzyme-hydrolysed casein & Phytic acid \\
Cowieson et al. [68] & Enzyme-hydrolysed casein & Phytic acid \\
Kluth and Rodehutscord [69] & Regression method & Cellulose \\
Morel et al. [70] & Enzyme-hydrolysed casein & B-Glucan \\
Onyango et al. [71] & Glucose & Phytic acid \\
Adedokun et al. [72] & Casein -regression method & Dietary electrolytes \\
Adedokun and Applegate [73] & Protein-free diet & Dietary electrolytes \\
Adedokun et al. [74] & Protein-free diet & Calcium level \\
Whitehouse et al. [75] & Protein-free diet & Lipids
\end{tabular}

This approach has its drawbacks [77], but represents a way forward to overcome the limitations of apparent digestibility. In the poultry industry, on the other hand, there is less agreement on what should constitute basal EAA losses.

The resistance in the poultry industry to agree on a constant basal EAA value arises from the extreme variability found in published estimates following the feeding of protein diets (Table 6). Even after the exclusion of EAA outliers, the coefficient of variation was in excess of $30 \%$ for most amino acids. Many interrelated factors contribute to the reported variability. The main animal factors comprise of class of birds, poultry species, protein status, age, body weight and health status. The dietary factors include type of purified protein, indigestible dietary marker and energy source. Interestingly, there had been some debate and confusion about the influence of energy sources (starch and dextrose) on EAA. Marked influence of the ratio of starch and dextrose in assay diets was reported in one study EAA [88]. Curiously this

Table 6 Reported variability in the basal endogenous flow ( $\mathrm{g} / \mathrm{kg}$ dry matter intake) in broiler chickens fed nitrogen-free diets ${ }^{\mathrm{a}}$

\begin{tabular}{|c|c|c|c|}
\hline Amino acids & Range of published values ${ }^{a}$ & Average $^{b}$ & Coefficient of variation, $\%^{\mathrm{b}}$ \\
\hline Aspartic acid & $0.34-1.64$ & 0.58 & 25.5 \\
\hline Threonine & $0.27-0.97$ & 0.50 & 18.4 \\
\hline Serine & $0.26-1.03$ & 0.45 & 24.1 \\
\hline Glutamic acid & $0.42-2.13$ & 0.77 & 27.6 \\
\hline Proline & $0.24-1.07$ & 0.43 & 45.4 \\
\hline Glycine & $0.21-0.83$ & 0.36 & 31.8 \\
\hline Alanine & $0.14-0.91$ & 0.30 & 28.5 \\
\hline Valine & $0.21-1.01$ & 0.37 & 25.4 \\
\hline Isoleucine & $0.16-0.86$ & 0.30 & 25.0 \\
\hline Leucine & $0.25-1.45$ & 0.43 & 30.2 \\
\hline Tyrosine & $0.12-0.64$ & 0.23 & 57.1 \\
\hline Phenylalanine & $0.15-0.83$ & 0.31 & 36.3 \\
\hline Histidine & $0.07-0.42$ & 0.15 & 37.2 \\
\hline Lysine & $0.16-1.24$ & 0.29 & 38.0 \\
\hline Arginine & $0.16-1.02$ & 0.29 & 32.8 \\
\hline Methionine & $0.05-0.36$ & 0.09 & 29.8 \\
\hline Cysteine & $0.03-0.55$ & 0.18 & 33.1 \\
\hline
\end{tabular}

a References: Siriwan et al. [31]; Adedokun et al. [32]; Ravindran et al. [57]; Adedokun et al. [72]; Adedokun et al. [73]; Adedokun et al. [74]; Ravindran et al. [80]; Adedokun et al. [81]; Adedokun et al. [82]; Adedokun et al. [83]; Golian et al. [84]; Ravindran et al. [85]; Woyengo et al. [86]; Soleimani et al. [87]; Kong and Adeola [88]; Ravindran et al. [89]; Toghyani et al. [90]; Cowieson et al. [91]; Osho et al. [92]; An et al. [93]; Cowieson et al. [94]

${ }^{b}$ Average values and variability were calculated after removal of the following extreme outliers: Adedokun et al. [32]; Adedokun et al. [73]; Kong and Adeola [88] 
study also reported extremely high EAA estimates (see Table 6). However, no such effects due to energy sources were seen in other studies [73] as well as in 16 studies in our laboratory. Methodological difference in the collection and processing of ileal digesta is one of the pivotal, and perhaps the most neglected, contributing factor as shown by Ravindran et al. [80]. Differences in analytical procedures and accuracy among laboratories (amino acids, marker) are equally, if not more, important but little-discussed causative factors.

In the author's opinion, despite its inherent limitations, the protein-free diet presents the best strategy among available techniques for the measurement of basal EAA losses. There may be four ways to address the impasse in the poultry industry on the agreement of a constant basal estimate. First, to measure basal losses in each digestibility assay. This will add to the cost and ideally must be avoided, but will suit research stations where digestibility assays are not carried out routinely. Second, since the assay conditions (assay diet composition, bird age, strain, housing etc.) are standardised within a research station and the variability will be minimal, average the basal EAA estimates across assays or over years and use this station-specific value for the correction. This approach will suit stations where the conduct of amino acid digestibility assays is routine. Third, collate available published data, remove outliers using appropriate statistical models and agree on average values that can be used globally as has been done in the pig industry. Finally, to conduct a collaborative 'ring test' involving several key research stations using pre-agreed standardised assay conditions and controls, as has been conducted for ileal amino acid digestibility assay [80], and develop estimates that could be used globally.

\section{Terminology used to describe digestible amino acids}

Before concluding, a note on the use of AA digestibility terminology in relation to different estimates of endogenous losses is relevant. In recent decades, the digestible amino acid system used by the poultry industry has shifted from excreta values to ileal-based values and several compilations of ileal amino acid digestibility of feed ingredients are now available [95-97]. Considerable confusion, however, still exists regarding the ileal digestibility terminologies used in the literature - apparent, true, standardised and real. In particular, the terms true vs. standardised digestibility are being used interchangeably in recent times and different definitions are being presented by different groups, creating confusion among end-users. For practical purposes, true and standardised digestibility refer to the same. In the pig industry, the use of the term 'standardised ileal digestibility (SID)' has become the norm [79] and also being increasingly used in poultry.

A further confusion arises from the use, by some researchers, of the term real digestibility, which includes the correction for the total endogenous losses and is related to the feeding of a specific ingredient [10, 41]. Real digestibility may be more reliable than true digestibility [98], but (as noted above) at the current time insufficient data are available on total EAA losses to seriously consider this system. It is suggested that this issue is probably more theoretical rather than practical and the merit of real versus true digestibilities in applied nutrition is questionable. For a detailed discussion on digestible amino acid systems, readers are referred to Moughan et al. [77].

\section{Conclusions}

Endogenous protein losses represent significant protein and energy maintenance costs to the animal. Quantification of these losses is clearly relevant to improve the efficiency of protein digestion and for the better understanding of the factors influencing these losses. The progress in the measurement and factors influencing the ileal endogenous amino acid flow in poultry was examined in this review. During the 1980's and 1990's, there was heightened research activity on the evaluation of isotopic and homoarginine techniques to better comprehend the insights of endogenous protein flow in animals. For unknown reasons, this interest has in EAA, in general, slowed down in recent years. All the techniques reported in this review have their own merits and limitations, and none are perfect. The present review is the first report identifying taurine as a component amino acid in the endogenous protein flow in poultry. It is recommended that future poultry assays on EAA losses include estimates for taurine. An array of techniques has been tested and evaluated to replace the protein-free diet for EAA flow measurements. Continued use of this century-old method [2] at the present time may seem archaic. Until other research techniques are refined and simplified, however, protein-free diets will continue to provide information to resolve important questions about EAA and protein nutrition. As seen, endogenous protein flow is a complex issue and one that deserves critical thinking and investigation.

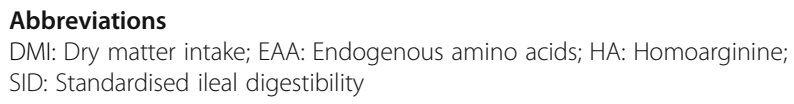

\section{Acknowledgements}

Not applicable.

Author's contributions

Sole author. The author(s) read and approved the final manuscript. 


\section{Funding}

Not applicable.

\section{Availability of data and materials}

Not applicable.

\section{Ethics approva \\ Not applicable.}

\section{Consent for publication}

Author approved the final manuscript.

\section{Competing interests}

Author declares no competing interest.

Received: 29 June 2020 Accepted: 16 November 2020

Published online: 06 January 2021

\section{References}

1. Armsby HP. The nutrition of farm animals. New York: The MacMillan Co. 1917.

2. Mitchell $\mathrm{HH}$. A method of determining the biological value of protein. J Biol Chem. 1924:58:873-903.

3. Kellner O. The scientific feeding of animals. 2nd ed, Translated by Goodwin W. London: Duckworth; 1926.

4. Ackerson CW, Blish MJ, Mussehl FE. The endogenous nitrogen of hens as affected by moulting. Poult Sci. 1926;5:153-61.

5. Bragg DB, Ivy CA, Stephenson EL. Methods for determining amino acid availability of feeds. Poult Sci. 1969;48:2135-7.

6. Ravindran V, Hew LI, Ravindran G, Bryden WL. A comparison of ileal digesta and excreta analysis for the determination of amino acid digestibility in feed ingredients for poultry. Br Poult Sci. 1999;40:266-74.

7. Nasset ES, Ju JS. Mixture of endogenous and exogenous protein in the alimentary tract. J Nutr. 1961;74:461-5.

8. Souffrant WB, Rerat A, Laplace JB, Darcy BV, Kohler R, Corring T, et al. Exogenous and endogenous contributions to nitrogen fluxes in the digestive tract of pigs fed a casein diet. iii. refluxing of endogenous nitrogen. Reprod Nutr Dev. 1993;33:373-82.

9. Moughan PJ. Amino acid digestibility and availability in foods and feedstuffs. In: Proceedings IXth Intl Symp. Dig. Physiol. in Pigs. Banff, Canada; 2003. p. 199-221.

10. Boisen S, Moughan PJ. Dietary influences on endogenous ileal protein and amino acid losses in the pig - a review. Acta Agric Scand Sec A. 1996:46: 154-64

11. Sibbald IR. Estimation of bioavailable amino acids in feedstuffs for poultry and pigs: a review with emphasis on balance experiments. Can J Anim Sci. 1987:67:221-30

12. Nyachoti CM, de Lange CFM, MCBride BW, Schulze H. Significance of endogenous gut nitrogen losses in the nutrition of growing pigs: a review. Can J Anim Sci. 1997;77:149-63.

13. Ravindran $\mathrm{V}$, Bryden WL. Amino acid availability in poultry - in vitro and in vivo measurements. Aust J Agric Res. 1999;50:889-908.

14. Adedokun SA, Adeola O, Parsons CM, Lilburn MS, Applegate TJ. Factors affecting endogenous amino acid flow in chickens and the need for consistency in methodology. Poult Sci. 2011;90:1737-48.

15. Adeola O, Xue PC, Cowieson AJ, Ajuwon KM. Basal endogenous losses of amino acids in protein nutrition and research for swine and poultry. Anim Feed Sci Technol. 2016:221:274-83.

16. Angkanaporn K, Bryden WL, Ravindran V. Endogenous amino acid losses in pigs and poultry: a review. Thai J Vet Med. 1996;26:7-27.

17. Parsons CM, Potter LM, Brown RD. Effect of dietary carbohydrate and of intestinal microflora on excretion of endogenous amino acids in poultry. Poult Sci. 1983;62:683-9.

18. Miner-Williams W, Moughan PJ, Fuller MF. Endogenous components of digesta protein from the terminal ileum of pigs fed a casein-based diet. J Agric Food Chem. 2009;57:2072-8.

19. Ravindran $V$, Hendriks $W H$. Endogenous amino acid flows at the terminal ileum of broilers, layers and adult roosters. Anim Sci. 2004;79:265-71.

20. Jansman AJM, Smink W, van Leeuwen P. Rademacher M. Evaluation through literature data of the amount and amino acid composition of basal endogenous crude protein at the terminal ileum of pigs. Anim Feed Sci Technol. 2002:98:49-60.

21. Corring $T$, Jung J. The amino acid composition of pig pancreatic juice. Nutr Rep Intl. 1972;6:187-90.

22. Juste C. Apports endogenes par les secretions digestives chez le porc. In: Laplace JP, Corring T, Rerat A, editors. Physiologie Digestive Chez le Porc. Paris: Institut National de la Recherche Agronomique; 1982. p. 155-73.

23. Lien KA, Sauer WC, Fenton M. Mucin output in ileal digesta of pigs fed a protein free diets. Z Ernahrungswiss. 1997;36:182-90.

24. Lien KA, Sauer WC, He JM. Dietary influences on the secretion into and degradation of mucin in the digestive tract of monogastric animals and humans. J Anim Feed Sci. 2001;10:223-45.

25. Montagne L, Piel C, Lalles JP. Effect of diet on mucin kinetics and composition: nutrition and health implications. Nutr Rev. 2004;62:105-14.

26. Haslewood GAD. Recent developments in our knowledge of bile salts. Physiol Revs. 1955;35:178-96.

27. Bremmer J. Species differences in the conjugates of free bile acids. Biochem J. 1958;63:507-13.

28. Schneeman BO, Chang I, Smith L, Lyman LR. Effect of dietary amino acids, casein and soybean trypsin inhibitors on pancreatic protein secretion in rats. J Nutr. 1987:107:281-8.

29. Likuski HJA, Dorrell HG. A bioassay for rapid determination of amino acid availability values. Poult Sci. 1978;57:1658-60.

30. Sibbald IR. A bioassay for available amino acids and true metabolisable energy in feedingstuffs. Poult Sci. 1979:58:668-75.

31. Siriwan P, Bryden WL, Annison EF. Use of guanidinated dietary protein to measure losses of endogenous amino acid in poultry. Br J Nutr. 1994;71: 515-29.

32. Adedokun SA, Utterback P, Parsons CM, Adeola A, Lilburn MS, Applegate TJ. Comparison of endogenous amino acid flow in broilers, laying hens and caecectomised roosters. Br Poult Sci. 2009;50:359-65.

33. Souffrant WB, Kohler R, Gebhardt G. Determination de l'azote endogene dans les contenus digestifs par la technique isotopique $\left({ }^{15} \mathrm{~N}\right)$. In: Laplace JP, Corring T, Rerat A, editors. Physiologie Digestive chez le Porc. 2e Seminaire International. Paris: Institute National de la Recherche Agronomique; 1982. p. $175-87$.

34. de Lange CFM, Souffrant WB, Sauer WC. Real ileal protein and amino acid digestibilities in feedstuffs for growing pigs as determined with the ${ }^{15} \mathrm{~N}$ isotope dilution technique. J Anim Sci. 1990;68:409-18.

35. Roos $\mathrm{N}$, Pfeuffer $\mathrm{M}$, Hagemeister $\mathrm{H}$. Labelling with ${ }^{15} \mathrm{~N}$ as compared with homoarginine suggests a lower prececal digestibility of casein in pigs. J Nutr. 1994;124:2404-9.

36. Danicke $\mathrm{S}$, Jeroch $\mathrm{H}$, Simon O. Endogenous $\mathrm{N}$-losses in broilers estimated by a $\left[{ }^{15} \mathrm{~N}\right]$-isotope dilution technique: effect of dietary fat type and xylanase addition. Arch Anim Nutr. 2000:53:75-97.

37. Cerrate S, Vignale SK, Ekmay R, England J, Coon C. Effect of dietary nutrients on ileal endogenous losses of threonine, cysteine, methionine, lysine, leucine and protein in broiler chicks. Animal. 2018;12:684-91.

38. Lien KA, Sauer WC, Mosenthin R, Souffrant W. Determination of ileal amino acid digestibilities with $\mathrm{N}$-isotope dilution techniques. In: Souffrant WB, Hagemeister H, editors. Proc. VIth Intl Symp. Dig. Physiol. in Pigs, vol. I. Bad Doberan: EAAP Publication No. 80; 1994. p. 31-4.

39. Letterme $P$, Thewis $A$, Francois $E$, van Leeuwen $P$, Wathelet $B$, Huisman J. The use of ${ }^{15} \mathrm{~N}$-labeled dietary proteins for determining true ileal amino acid digestibilities is limited by their rapid recycling in the endogenous secretions of pigs. J Nutr. 1996;126:2188-98.

40. Moughan PJ, Souffrant WB, Hodgkinson SM. Physiological approaches to determining gut endogenous amino acid flows in the mammal. Arch Anim Nutr. 1998:51:237-52.

41. Gabert VM, Canibe N, Jorgensen H, Eggum BO, Sauer WC. Use of N-amino acid isotope dilution techniques to determine endogenous amino acids in ileal digesta in growing pigs. Acta Agric Scand Sect A Anim Sci. 1997;47: 168-77.

42. Xu M, Yao JH, Wang KN, Meng De L, Luo DY, Wu XB, et al. ${ }^{3} \mathrm{H}$-leucine single injection method for determining endogenous amino acid losses of broilers. Nutrition. 2011:27:829-32.

43. Makkar HP. A review of the use of isotopic and nuclear techniques in animal production. Anim Feed Sci Technol. 2008:140:418-43.

44. Hagemeister $\mathrm{H}$, Erbersdobler $\mathrm{H}$. Chemical labelling of dietary protein by transformation of lysine to homoarginine: a new technique to follow intestinal digestion and absorption. Proc Nutr Soc. 1985;44:133a. 
45. Rutherfurd SM. Use of guanidination reaction for determining reactive lysine, bioavailable lysine and gut endogenous lysine. Amino Acids. 2015; 47(9):1805-15

46. Yin J, Ren W, Hou Y, Wu M, Xian H, Duan J, et al. Use of homoarginine for measuring true ileal digestibility of amino acids in food protein. Amino Acids. 2015:47:1795-803.

47. Ravindran $V$. Feed-induced specific ileal endogenous amino acid losses: measurement and significance in the protein nutrition of monogastric animals. Anim Feed Sci Technol. 2016;221:304-13.

48. Angkanaporn K, Ravindran V, Mollah Y, Bryden WL. Secretion of homoarginine into the gut of chickens. Vet Res Commun. 1997;21:161-7.

49. Ravindran V, Hew LI, Bryden WL. Influence of guanidination on apparent ileal amino acid digestibility in some protein sources for broilers. Poult Sci. 1998;77:873-7.

50. Maga JA. Measurement of available lysine using the guanidination reaction. J Food Sci. 1981;46:132-4.

51. Rutherfurd SM, Moughan PJ. Guanidination of lysine in selected dietary proteins. J Agric Food Chem. 1990;38:209-11.

52. Imbeah M, Angkanaporn K, Ravindran V, Bryden WL. Investigations on the guanidination of protein. J Sci Food Agric. 1996;72:213-8.

53. Ravindran V, Imbeah M, Angkanaporn K, Bryden WL. Guanidination of lysine in cottonseed protein. J Agric Food Chem. 1996;44:1812-5.

54. Caine WR, Sauer W, Huang GS, Diebold G, Schollenberger M, Mosenthein R. Influence of guanidination on apparent ileal digestibility of amino acids in pigs fed diets with soybean meal, rapeseed meal or peas as a protein source. Livest Sci. 2008;116:300-8.

55. Angkanaporn $\mathrm{K}$, Choct M, Bryden WL, Annison EF, Annison G. Effect of wheat pentosans on endogenous amino acid losses in chickens. J Sci Food Agric. 1994;66:399-404.

56. Angkanaporn K, Ravindran V, Mollah Y, Bryden WL. Additivity of apparent and true ileal amino acid digestibilities in soybean meal, sunflower meal and meat and bone meal for broilers. Poult Sci. 1996;75:1098-103.

57. Ravindran V, Hew LI, Ravindran G, Bryden WL. Endogenous amino acid flow in the avian ileum: quantification using three techniques. Br J Nutr. 2004;92: 217-23.

58. Furuya S, Kaji Y. Estimation of the true ileal digestibility of amino acids and nitrogen from their apparent values for growing pigs. Anim Feed Sci Technol. 1989:26:271-85.

59. Fan MZ, Sauer WC, McBurney MI. Estimation by regression analysis of endogenous amino acid levels in digesta collected from the distal ileum of pigs. Can J Anim Sci. 1995;73:2319-28.

60. Short FJ, Wiseman J, Boorman KN. Application of a method to determine ileal digestibility in broilers of amino acids in wheat. Anim Feed Sci Technol. 1999;79:195-209.

61. Rodehutscord M, Kapocius M, Timmler R, Dieckmann A. Linear regression to study amino acid digestibility in broiler chickens. Br Poult Sci. 2004;45:85-92.

62. Shastak Y, Witzig M, Hartung K, Rodehutscord M. Comparison of retention and prececal digestibility measurements in evaluating mineral phosphorus sources in broilers. Poult Sci. 2012;91:2201-9.

63. Mutucumarana R, Ravindran V, Ravindran G, Cowieson AJ. Measurement of true ileal digestibility and total tract retention of phosphorus in corn and canola meal for broiler chickens. Poult Sci. 2014a;93:412-9.

64. Mutucumarana R, Ravindran V, Ravindran G, Cowieson AJ. Measurement of true ileal digestibility of phosphorus in some feed ingredients for broiler chickens. J Anim Sci. 2014b;92:5520-9.

65. Cowieson AJ, Bedford MR, Selle PH, Ravindran. Phytate and microbial phytase: Implications for endogenous nitrogen losses and nutrient availability. Wld's Poult Sci J. 2009;65:401-18.

66. Siriwan P, Bryden WL, Annison EF. Effects of dietary fibre and protein levels on endogenous protein secretions in chickens. Proc Nutr Soc Aust. 1989;14: 143.

67. Cowieson AJ, Ravindran V. Effect of phytic acid and microbial phytase on the flow and amino acid composition of endogenous protein at the terminal ileum of growing broiler chickens. Br J Nutr. 2007;98: 745-52.

68. Cowieson AJ, Selle PH, Ravindran V. Influence of dietary phytic acid and source of microbial phytase on ileal endogenous amino acid flows in broiler chickens. Poult Sci. 2008:87:2287-99.

69. Kluth $\mathrm{H}$, Rodehutscord M. Effect of inclusion of cellulose in the diet on the inevitable endogenous amino acid losses in the ileum of broiler chicken. Poult Sci. 2009;88:1199-205.
70. Morel PC, Padilla RS, Ravindran G. Effect of non-starch polysaccharides in mucin secretion and endogenous amino acid losses. Asian-Aust J Anim Sci. 2003;16:1332-8

71. Onyango EM, Asem EK, Adeola O. Phytic acid increases mucin and endogenous amino acid losses from the gastrointestinal tract of chickens. $\mathrm{Br}$ J Nutr. 2009;101:836-42.

72. Adedokun SA, Pescatore AJ, Ford MJ, Jacob JP, Helmbrecht A. Examining the effect of dietary electrolyte balance, energy source and length of feeding of nitrogen-free diets on ileal endogenous amino acid losses in broilers. Poult Sci. 2017;96:3351-60.

73. Adedokun SA, Applegate TJ. Dietary electrolyte balance influences ileal endogenous amino acid losses in broiler chickens. Poult Sci. 2014;93:935-42.

74. Adedokun SA, Pescatore AJ, Ford MJ, Ao T, Jacob JP. Investigating the effect of dietary calcium levels on ileal endogenous amino acid losses and standardized ileal amino acid digestibility in broilers and laying hens. Poult Sci. 2018;97:131-9.

75. Whitehouse TH, Zaefarian F, Abdollahi MR, Ravindran V. Dietary fat inclusion decreases endogenous amino acid losses in broiler chickens. Proc Aust Poult Sci Symp. 2020;31:61.

76. Lemme A, Ravindran V, Bryden WL. Ileal digestibility of amino acids in feed ingredients for broilers. WId's Poult Sci J. 2004;60:421-35.

77. Moughan PJ, Ravindran V, Sorbara JOB. Dietary protein and amino acids consideration of the undigestible fraction. Poult Sci. 2014;93:2400-10.

78. Stein HH, Seve B, Fuller MF, Moughan PJ, de Lange CFM. Amino acid bioavailability and digestibility in pig feed ingredients. J Anim Sci. 2007;85: 172-80.

79. NRC. Nutrient requirements of swine, Animal nutrition series, National Research Council of the National Academies. Washington DC: The National Academies Press; 2012.

80. Ravindran V, Adeola O, Rodehutscord M, Kluth $\mathrm{H}$, van der Klis JD, van Eerden $\mathrm{E}$, et al. Determination of ileal digestibility of amino acids in raw materials for broiler chickens - results of collaborative studies and assay recommendations. Anim Feed Sci Technol. 2017;225:62-72.

81. Adedokun SA, Parsons CM, Lilburn MS, Adeola O, Applegate TJ. Standardized ileal amino acid digestibility of meat and bone meal from different sources in broiler chicks and turkey poults with a nitrogen-free or casein diet. Poult Sci. 2007a;86:2598-607.

82. Adedokun SA, Lilburn MS, Parsons CM, Adeola O, Applegate TJ. Comparison of ileal endogenous amino acid flows in broiler chicks and turkey poults. Poult Sci. 2007b;86:1682-9.

83. Adedokun SA, Parsons CM, Lilburn MS, Adeola O, Applegate TJ. Endogenous amino acid flows in broiler chicks is affected by the age of birds and method of estimation. Poult Sci. 2007c;86:2590-7.

84. Golian A, Guether W, Hoehler D, Jahanian H, Nyachoti CM. Comparison of various methods for endogenous ileal amino acid flow determination in broiler chickens. Poult Sci. 2008;87:706-12

85. Ravindran V, Morel PCH, Rutherfurd SM, Thomas DV. Endogenous flow of amino acids in the avian ileum is increased by increasing dietary peptide concentrations. Br J Nutr. 2009;101:822-8.

86. Woyengo TA, Cowieson AJ, Adeola O, Nyachoti CM. Ileal digestibility and endogenous flow of minerals and amino acids: responses to dietary phytic acid in piglets. Br J Nutr. 2009;102:428-33.

87. Soleimani AF, Kasim A, Alimon A, Meimandipour A, Zulkifil I. Ileal endogenous amino acid flow of broiler chickens under high ambient temperature. Anim Physiol Anim Nutr. 2010:94:641-7.

88. Kong C, Adeola A. lleal endogenous amino acid flow response to nitrogenfree diets with differing ratios of corn starch and in broiler chickens. Poult Sci. 2013;92:1276-82

89. Ravindran V, Abdollahi MR, Bootwalla SM. Nutrient analysis, metabolizable energy and digestible amino acids of soybean meals of different origin for broilers. Poult Sci. 2014;93:2567-77.

90. Toghyani M, Rodgers N, lji PA, Swick RA. Standardized ileal amino acid digestibility of expeller-extracted canola meal subjected to different processing conditions for starter and grower broiler chickens. Poult Sci. 2015;94:992-1002

91. Cowieson AJ, Sorbara JOB, Pappenberger G, Abdollahi MR, Roos FF, Ravindran V. Additivity of apparent and standardized ileal amino acid digestibility of corn and soybean meal in broiler diets. Poult Sci. 2019:98: 3722-8.

92. Osho SO, Babatunde OO, Adeola O. Additivity of apparent and standardized ileal digestibility of amino acids in wheat, canola meal, and sorghum 
distillers dried grains with solubles in mixed diets fed to broiler chickens. Poult Sci. 2019;98:1333-40.

93. An SH, Sung JY, Kang H-K, Kong C. Additivity of ileal amino acid digestibility in diets containing corn, soybean meal, and corn distillers dried grains with solubles for male broilers. Animals. 2020;10:933.

94. Cowieson AJ, Sorbara J-O, Pappenberger G, Abdollahi MR, Ravindran V. Toward standardized amino acid matrices for exogenous phytase and protease in corn-soybean meal-based diets for broilers. Poult Sci. 2020;99: 3196-206.

95. Bryden WL, Li X, Ravindran G, Hew LI, Ravindran V. lleal digestible amino acid values in feedstuffs for poultry. Canberra: Rural Industries Research and Development Corporation; 2009.

96. Blok MC, Dekker RA. Table 'standardized ileal digestibility of amino acids in feedstuffs for poultry'. CVB documentation report $\mathrm{nr} 61$. Wageningen: Wageningen Livestock Research; 2017.

97. Evonik. AMINODAT 5.0. Hanau-Wolfgang: Evonik Nutrition \& Care GmbH; 2017.

98. Batterham ES. Availability and utilisation of amino acids for growing pigs. Nutr Res Rev. 1992;5:1-18.

Ready to submit your research? Choose BMC and benefit from:

- fast, convenient online submission

- thorough peer review by experienced researchers in your field

- rapid publication on acceptance

- support for research data, including large and complex data types

- gold Open Access which fosters wider collaboration and increased citations

- maximum visibility for your research: over $100 \mathrm{M}$ website views per year

At $\mathrm{BMC}$, research is always in progress.

Learn more biomedcentral.com/submissions 